\title{
Handwashing and barrier practices among Cameroonian dental professionals
}

\author{
Agbor MA ${ }^{1}$, Azodo CC $^{2}$ \\ ${ }^{1}$ Dental department, Nkwen Baptist Health Centre, Bamenda, Cameroon \\ ${ }^{2}$ Department of Periodontics, University of Benin Teaching Hospital, Nigeria
}

Agbor MA, Azodo CC

Handwashing and barrier practices among Cameroonian dental professionals. Tanz Dent J 2010, 16 (2): 35-38

\begin{abstract}
:
Objective: To assess handwashing and barrier practices among Cameroonian dental professionals. Materials and Methods: A questionnaire-based cross-sectional study of Cameroon dental professionals was conducted in the second half of 2009. Results: A total of 41 dental professionals were recruited. Infection control activities in the clinic were supervised mainly by $31 \%$ of dentists and $38.6 \%$ of dental therapists. Less than half of the respondents reported good handwashing practice. More than half (63.4\%) wash their hands with running water and liquid soap and 63.9\% dry their washed hands with towel in the clinic. Facemasks and eye glasses were the barriers most commonly used by the respondents. Conclusion: Deficiencies existed in handwashing and barrier practices among the studied Cameroonian dental professionals. Infection control guidelines was also lacking in majority of the dental clinic where the studied dental professionals were recruited. The introduction of mandatory continuing education on handwashing and barrier practices may improve compliance with the recommended standard.
\end{abstract}

Keywords: Infection control, handwashing, gloves, dental professionals, Cameroon

Correspondence: Dr C.C. Azodo, Department of Periodontics, University of Benin Teaching Hospital

New Dental Complex, P.M.B 1111 Ugbowo, Benin-City, Edo State, Nigeria 300001,

Email: clementazodo@yahoo.com, Phone: +2348034051699

\section{Introduction}

Infection control is a component of dentistry that has undergone tremendous changes since the discovery of human immunodeficiency virus (HIV). Compliance with guidelines on infection control in dentistry, formulated by the Center for Disease Control, is considered proper infection control practice (1). Handwashing and barrier usage are recognized components of infection control in the medical and dental healthcare delivery (1). Handwashing is the first step in achieving infection control in dentistry and during other surgical procedures. In dentistry, handwashing's role in interrupting the transmission of microorganisms is important as hands are usually exposed to the site of operation. Achieving an improvement in hand hygiene practices, with the ultimate goal of promoting a strong patient safety culture, was the main objective of the First Global Patient Safety Challenge, launched by the World Health Organization (2).

Dental care professionals are at high risk of crossinfection while treating patients because numerous infective agents present in dental practice can easily be transmitted by blood or saliva via direct or indirect contact, droplets, aerosols, or contaminated instruments and equipment. Droplets and aerosols, which is mode of cross infection in dentistry, is generated by the use of rotary handpieces, air-water syringes, ultrasonic scaling devices, and other instruments may enter the respiratory system and the eyes of the dental professionals, creating a risk of disease transmission $(3,4)$. Barriers in form of protective eye wear, face masks, gloves, clinical coat etc. worn over the face, eyes, nose, mouth, hands and clothes by dental professionals are usually sufficient to prevent cross infection by preventing contamination through inhalational and mucocutaneous exposure to infective agents. The use of personal protection equipment as barrier controls to prevent skin and mucous membrane exposures is also considered as one of the cornerstones of the practice of standard precautions. Gloves reduce the likelihood of transmission of microorganisms on healthcare workers' hands to patients during surgery or patient-care procedures (5). Face masks and protective eyewear are important in reducing contamination of the mucous membranes and skin surrounding the eyes, nose, and mouth as well as injury and infections. Protective clothing also function to prevent contamination of private clothing and to protect the skin of dental professionals from exposures to blood and body fluids. Proper infection control practices is hampered in developing countries due to limited financial resources, non availability of sophisticated equipment and inadequate supply of materials for infection control (6-9). 
Cameroon has no professional or academic institution responsible for the monitoring of dental infection control practices. Dentists in Cameroon and some dental auxiliaries are foreign trained from various countries, making it difficult to have a uniform infection control standard. The first step in creating a model of proper infection control practice in Cameroon should be the assessment of the present level of adherence to international standard on infection control. The objective of this study was to assess handwashing and barrier practices among Cameroonian dental professionals.

\section{Materials and methods}

After obtaining Ethical approval from the Provincial Delegations of the Ministry of Public Health of the 4 selected provinces out 10 provinces, a questionnaire based cross-sectional study was conducted among the dental professionals. The 12-item, self-administered questionnaire elicited information on demography, existence of a guideline for infection control, monitoring of infection control, handwashing practices and the use of protective barriers. Informed consent was obtained from the participants after being informed of the objective of the study and assured of strict confidentiality of their responses. Participation was voluntary and no incentive was offered. Epi-info version 6 was used for data analysis. Test for significance was done with Chi square. $\mathrm{P}<0.05$ was considered significant. The results were presented in tabular forms.

\section{Results}

Majority (43.9\%) of the respondents were in the 3140 year age group and males made up $58.5 \%$. Dentists constituted $31.7 \%$ and the remaining $68.3 \%$ were dental auxiliaries which include dental surgery assistants, dental therapists and dental technologists. About $30 \%$ of the respondents work in dental clinics located in rural areas while $70.7 \%$ work in urban areas. A total of 18 (43.9\%) reported the existence of infection control guideline in their clinic. The likelihood of infection control guideline existing was higher for missionary owned clinic followed by public owned clinic and private public owned clinic, (Table 1). Proper handwashing practice was reported by $43.9 \%$ of the respondents. Some respondents practice handwashing only on arrival to work (12.2\%), before seeing a patient $(4.9 \%)$ or only after seeing a patient (36.6\%). (Table 2 )
Table 1 Distribution of dental clinics by type of dental practice and the existence of infection control guidelines

\begin{tabular}{lcccc}
\hline \multirow{2}{*}{$\begin{array}{l}\text { Type of dental } \\
\text { clinic }\end{array}$} & \multicolumn{3}{l}{$\begin{array}{l}\text { Existence of infection } \\
\text { control guidelines }\end{array}$} \\
\cline { 2 - 5 } & \multicolumn{2}{c}{ Yes } & \multicolumn{2}{c}{ No } \\
\cline { 2 - 5 } & $\mathrm{n}$ & $\mathbf{( \% )}$ & $\mathrm{n}$ & $\mathbf{( \% )}$ \\
\hline Private & 2 & 18.2 & 9 & 81.8 \\
Public & 5 & 31.3 & 10 & 68.7 \\
Missionary & 11 & 78.6 & 4 & 21.4 \\
Total & 18 & 43.9 & 23 & 56.1 \\
\hline
\end{tabular}

A total of 26 (63.4\%) wash their hand with running water and liquid soap, $63.4 \%$ dry their washed hands with towel in the clinic, $26.8 \%$ used disposable paper napkin and 7.3\% used dry air. (Table 2)

The sterile surgical type of glove was used by $29.3 \%$ of the dental professionals and $56.1 \%$ use the non sterile examination type. Only $2.4 \%$ use the heavy duty type. About $19.5 \%$ wash their hands before gloving, 26.8\% wash their hands after gloving and $7.3 \%$ don't use gloves for patient's examination (Table 2).

A total of $13(31.7 \%)$ of the respondents use eye glasses, facemask, surgical scrubs and caps for their protection, while 14 (34.1\%) use face mask alone, $12.2 \%$ use only eye glasses and $9.8 \%$ protective clothing and caps (Table 3).

\section{Discussion}

In this study, two-thirds of the studied dental clinics have existing guidelines for infection control. This was similar to the finding in an earlier study (10) where $70 \%$ had management policy on infection control. This study revealed that infection control activities were supervised mainly by dentists and dental therapists in $31 \%$ and $38.6 \%$ of the clinic respectively. This implies that all the dental practitioners can be useful in that regard, if properly trained. The study also revealed that the guidelines are mostly used in missionary owned clinic than both the government and privately owned clinics. There is therefore a need for the authority in charge of the government and privately owned clinic to ensure compliance with the existing guidelines. 
Table 2: Hand washing and gloving practices among the respondents $(n=41)$

\begin{tabular}{|c|c|c|}
\hline Parameter & $\begin{array}{r}\text { Frequency } \\
\text { (no.) }\end{array}$ & $\begin{array}{r}\begin{array}{r}\text { Percent } \\
(\%)\end{array} \\
\end{array}$ \\
\hline \multicolumn{3}{|l|}{$\begin{array}{l}\text { When do you wash } \\
\text { your hands? }\end{array}$} \\
\hline When I come to work & 5 & 12.2 \\
\hline Before I see a patient & 2 & 4.9 \\
\hline After I see a patient & 15 & 36.6 \\
\hline All of the above & 18 & 43.9 \\
\hline None of the above & 1 & 2.4 \\
\hline \multicolumn{3}{|l|}{$\begin{array}{l}\text { What do you use to } \\
\text { wash hands? }\end{array}$} \\
\hline Water and soap & 5 & 12.2 \\
\hline $\begin{array}{l}\text { Running water and soap } \\
\text { tablet }\end{array}$ & 9 & 22.0 \\
\hline $\begin{array}{l}\text { Running water and } \\
\text { liquid soap }\end{array}$ & 26 & 63.4 \\
\hline Only water & 1 & 2.4 \\
\hline \multicolumn{3}{|l|}{$\begin{array}{l}\text { What do you dry your } \\
\text { hands with? }\end{array}$} \\
\hline Towel in the clinic & 26 & 63.4 \\
\hline $\begin{array}{l}\text { Disposable paper } \\
\text { napkin }\end{array}$ & 11 & 26.8 \\
\hline Dry air & 3 & 7.3 \\
\hline All above & 1 & 2.4 \\
\hline \multicolumn{3}{|l|}{ Gloving } \\
\hline $\begin{array}{l}\text { I don't use gloves to } \\
\text { examine patient }\end{array}$ & 30 & 73.2 \\
\hline $\begin{array}{l}\text { I use glove both to } \\
\text { examine and treat } \\
\text { patient }\end{array}$ & 11 & 26.8 \\
\hline
\end{tabular}

Handwashing is the single, most critical measure for reducing the risk of transmitting organisms to patients and health care providers (11). Hand hygiene, when performed correctly, will remove transient microorganisms from the surface of the skin. In this study, less than half (43.9\%) of the respondents exhibited good handwashing practice by washing their hands on coming to work, before, and after caring for patients. This calls for an urgent intervention especially since it has been reported that interventional hand-hygiene program resulted in increased compliance with handwashing guidelines and also brought about significant changes in health workers' attitudes, beliefs, and knowledge on hand hygiene (12). Poor hand hygiene compliance has been recorded among health workers and visitors in the intensive care units of a hospital in Thailand (13) although better compliance was reported by some other previous studies done in Malaysia (14) and the United state of America (15).
The gloving pattern reported in this study is similar to that previously reported in Canada where handwashing was done by a significant proportion of the dentists before gloving and after removing gloves $(16,17)$. The results show that the method used for handwashing is acceptable but that used for drying of hands was unacceptable. Handwashing with liquid soap under running water is the recommended infection control practice, as it reduces cross contamination that may be caused by continuous contact with soap by many workers in the same facility. In this study, more than half of the workers (63.4\%) washed their hands with liquid soap and running water. The accepted modes of drying of the hand are the use of disposable paper napkins or dry air. This eliminates the communal hand cleaning which results in re-contamination. In this study, $26.8 \%$ used disposable paper napkin and $7.3 \%$ used dry air. More than half $(63.9 \%)$ of the respondents used the communal towels in the clinic which is unacceptable as repeated contacts from several individuals would expose them to cross contamination.

Ideally, all persons in direct contact with patients should wear non sterile gloves routinely. They must be worn for all dental procedures including extra and intra-oral examination and not only for those procedures where there is a possibility of bleeding. A new pair of gloves should be used for each patient and may need to be changed during a procedure if exposed to contamination. In this study, only $26.8 \%$ wear glove during both examination and treatment of patients. There is an obvious deficiency in the gloving practice reported in this study and nonavailability of materials for infection control previous reported in developing countries may be the reason (18).

Table 3: Barrier usage among the respondents

\begin{tabular}{lrr}
\hline Barrier & Number & Percent \\
\hline Face masks & & 34.1 \\
& 14 & \\
Eye glasses & 5 & 12.2 \\
Protective clothing & 4 & 9.8 \\
Caps & 4 & 9.8 \\
All above & 13 & 31.7 \\
None above & 1 & 2.4 \\
\hline Total & $\mathbf{4 1}$ & $\mathbf{1 0 0 . 0}$ \\
\hline
\end{tabular}


Protective barriers reduce the risk of exposure of the healthcare worker's skin or mucous membranes to potentially infective materials. Consistent use of masks and protective eyewear or face shields should reduce the incidence of contamination of mucous membranes of the mouth, nose, and eyes (19). The use of protective barrier in this study is less than optimal. A study done in Jordan exclusively on dentist reported a better use of protective barriers (20). Although, 41 respondents recruited, is a small sample but it represented approximately 20\% of dental professionals. The findings may represent a true picture of dental professionals in Cameroon. Even though these research findings emanate from self reporting data, it stands out as useful data for interventional program and policy formulation.

\section{Conclusion}

Deficiencies existed in handwashing and barrier practices among the studied Cameroonian dental professionals. Infection control guideline was also lacking in majority of the dental clinic where the studied dental professionals were recruited. Improvement in handwashing and barrier practices is necessary in Cameroonian dental practice because of its importance in the prevention of the transmission of bloodborne pathogens and drug-resistant microorganisms. There is also a need to formulate a uniform guideline for infection control. The introduction of mandatory continuing education on handwashing and barrier practices may improve compliance with recommended standard.

\section{References}

1. CDC. Recommended Infection-Control Practices for Dentistry, 1993. MMWR 1993; 42: (RR-8).

2. Allegranzi B, Pittet D. Role of hand hygiene in healthcare-associated infection prevention. J Hosp Infect. 2009; 73:305-15.

3. Bennett AM, Fulford MR, Walker JT, Bradshaw DJ, Martin MV, Marsh PD. Microbial aerosols in general dental practice. Br Dent J. 2000; 189:664-7.

4. Harrel SK, Molinari J. Aerosols and splatter in dentistry: a brief review of the literature and infection control implications. J Am Dent Assoc. 2004; 135:429-37.

5. Palenik CJ. Gloves in the dental office: their use and effectiveness. Dent Today. 2004; 23:64-7.

6. Sofola OO, Savage KO. Assessment of the compliance of Nigerian dentists with infection control: a preliminary study. Infect Control Hosp Epidemiol. 2003; 24:737-40.
7. Chidzonga M, Makoni F, Mahomva L. Infection control among dental therapists in Zimbabwe. Cent Afr J Med. 2006; 52:83-7.

8. Kaimenyi JT, Ndung'u FL. Knowledge, practices and attitudes towards HIV positive and AIDS patients among dental auxiliaries. East Afr Med J. 1994; 71:304-10.

9. Wood PJ. Infection control practices of Rhode Island dental hygienists and certified dental assistants. J Dent Hyg. 1995; 69:212-22.

10. Smith A, Creanor S, Hurrell D, Bagg J, McCowan M. Management of infection control in dental practice. J Hosp Infect. 2009; 71:353-8.

11. Akyol A, Ulusoy H, Ozen I. Handwashing: a simple, economical and effective method for preventing nosocomial infections in intensive care units. J Hosp Infect. 2006; 62:395-405.

12. Creedon SA. Health care workers' hand decontamination practices: an Irish study. Clin Nurs Res. 2006; 15:6-26.

13. Patarakul K, Tan-Khum A, Kanha S, Padungpean D, Jaichaiyapum OO. Cross-sectional survey of handhygiene compliance and attitudes of health care workers and visitors in the intensive care units at King Chulalongkorn Memorial Hospital. J Med Assoc Thai. 2005; 88 Suppl 4:S287-93.

14. Katherason SG, Naing L, Jaalam K, Nik Mohamad NA, Bhojwani K, Harussani ND, Ismail A. Hand decontamination practices and the appropriate use of gloves in two adult intensive care units in Malaysia. $\mathrm{J}$ Infect Dev Ctries. 2010; 4:118-23.

15. Myers R, Larson E, Cheng B, Schwartz A, Da Silva $\mathrm{K}$, Kunzel C. Hand hygiene among general practice dentists: a survey of knowledge, attitudes and practices. J Am Dent Assoc. 2008; 139:948-57.

16. McCarthy GM, MacDonald JK. Improved compliance with recommended infection control practices in the dental office between 1994 and 1995. Am J Infect Control. 1998; 26:24-8.

17. McCarthy GM, Koval JJ, MacDonald JK. Compliance with recommended infection control procedures among Canadian dentists: results of a national survey. Am J Infect Control. 1999; 27:377-84.

18. Uti OG, Gbemisola A. Agbelusi GA, Jeboda SA, Ogunbodede E. Infection control knowledge and practices related to HIV among Nigerian dentists. J Infect Dev Ctries 2009; 3:604-610.

19. Beekmann SE, Vlahov D, Koziol DE, McShalley ED, Schmitt JM, Henderson DK. Temporal association between implementation of Universal Precautions and a sustained, progressive decrease in percutaneous exposures to blood. Clin Infect Dis 1994; 18:562-9.

20. AlNegrish A, Al Momani AS, Al Sharafat F. Compliance of Jordanian dentists with infection control strategies. Int Dent J. 2008; 58:231-6. 